\title{
Mediação Interdisciplinar e sua aplicação no Ambiente Escolar: construção da dignidade humana e disseminação da cultura da paz.
}

\author{
Maria Hortência Cardoso Lima* \\ Luciana Aboim Machado Gonçalves da Silva**
}

\section{RESUMO}

A cultura do litígio permeia a sociedade brasileira conduzindo os indivíduos a inúmeros conflitos dos quais as instituições de ensino não ficam de fora. Não se concebe modificar uma cultura sem se cogitar em investimentos no processo educacional. As famílias dos atores do ambiente escolar necessitam de atendimento para inclusão, mobilização, e desenvolvimento de ações voltadas para a paz, práticas colaborativas e soluções pacíficas. A mediação interdisciplinar se insere nesse contexto, adequando-se a tais exigências. Tal prática, incorporada no ambiente escolar, tende a se irradiar para a sociedade, garantindo tratamento digno e a construção de um caminho de paz.

Palavras-chave: mediação; educação; cultura; pacificação social; interdisciplinaridade.

\section{The Interdisciplinary Mediation and its application in the School Environment: construction of human dignity and dissemination of the culture of peace.}

\begin{abstract}
The culture of litigation permeates Brazilian society, leading individuals to countless conflicts where educational institutions are not left out. It is not conceivable to modify a culture without considering itself in investments of actions in the educational process. The families of this environment’s actors need assistance for inclusion, mobilization, and actions development

\footnotetext{
* Mestranda em Direito(UFS). Especialista em Direito de Família e Sucessões (Estácio/SE). Graduada em Direito (Estácio/SE); Licenciada em História(UFS). Instrutora de mediação (CNJ). Mediadora (CEJUSC/TJSE). Av. Central, 250, Olaria, Aracaju/SE CEP 49092-693; Email: hortencia.cejuscec@gmail.com.

** Professora(UFS).Doutora em Direito do Trabalho(USP).Mestre em Direito do Trabalho, especialista em Direito do Trabalho e Processual Civil(PUC/SP).Pós-doutoranda em Direito(UFBA e Università degli studi di Chieti).Vice-Presidente "Asociación Iberoamericana de Derecho de Trabajo". Av. Marechal Rondon, s/n. Jardim Rosa Elze. São Cristóvão/SE. CEP: 49100-000.Email: lucianags.adv@uol.com.br
} 
focused on peace, collaborative practices and peaceful solutions. Interdisciplinary mediation fits into this context by adapting to these requirements. Such practice, incorporated into the school environment tends to radiate to society, guaranteeing dignified treatment and building a path of peace.

Keywords: mediation; education; culture; social pacification; interdisciplinarity.

\section{INTRODUÇÃO}

A mediação de conflitos tem ocupado, nos últimos anos, um significativo espaço no contexto jurídico brasileiro por representar uma prática alternativa diferenciada para solução de conflitos e por estar sendo implantada no Poder Judiciário sob a forma de política pública.

A crise instaurada no Judiciário desencadeou a busca de novas abordagens para a solução dos conflitos e alcance da justiça mais próxima do que cada um almeja. A participação na construção das soluções levou o jurisdicionado a apresentar uma maior satisfação com os resultados obtidos. Tal fato, revelou a autocomposição como uma possibilidade de tratamento de conflitos no Poder Judiciário a se somar com o tradicional atendimento jurisdicional heterocompositivo.

A inserção de práticas autocompositivas em ambiente diverso do judicial, a exemplo do ambiente escolar, revela-se de extrema importância em nossa sociedade em virtude de propiciar o desenvolvimento de habilidades comunicacionais no processo educativo de formação do indivíduo voltadas à pacificação.

A nossa sociedade, em função da forma tradicional de educação que estimula unicamente a competição, desenvolveu um alto nível de embates no enfrentamento aos conflitos, de tal sorte que a sua grande maioria assume proporções máximas de litigiosidade e disputas, culminando, muitas vezes, com atitudes violentas e sérias dificuldades para uma solução direta pelos próprios envolvidos. Essa situação merece uma séria reflexão acerca dessas posturas e suas consequências danosas no meio social, sendo esta uma das propostas de análise do presente artigo.

A cultura praticada e ensinada no ambiente familiar se reproduz e se soma com o que é apreendido nas escolas, sendo salutar questionar se não seria conveniente e apropriada a inserção de práticas de autocomposição no processo de formação do individuo, educando-o 
para superação de conflitos com outras possibilidades que não a violência e a litigância excessivas dentro das escolas.

As famílias dos atores do ambiente escolar compõem o conselho escolar, órgão decisório, participando direta ou indiretamente dos conflitos e de suas alternativas para soluções, juntamente com professores, discentes, coordenadores e direção. Sua interferência ou mesmo ausência nesse cenário se reflete diretamente nos resultados da instituição e da vida social de todos os envolvidos.

A cultura da paz se constrói mediante ações que combatam os comportamentos competitivos e desarmônicos e requer para seu fortalecimento um aprendizado de outras formas educacionais voltadas para o diálogo e o consenso, respeitando-se as diferenças.

A metodologia do modelo descritivo-analítico, em essência, será a eleita para a investigação em referenciais teóricos bibliográficos acerca da mediação interdisciplinar e sua aplicação no ambiente ensino aprendizagem.

Pretende-se estabelecer reflexões acerca da cultura do litígio existente e disseminada ordinariamente que culmina, usualmente, em atitudes violentas; sugerir a implantação da mediação de conflitos como uma prática educacional e meio de promoção dos diálogos, sob os mais diversos temas, nas escolas, a exemplo do bullying e conflitos envolvendo as famílias nesse contexto; e, ainda, argumentar sobre meios efetivos para a construção da cultura da paz, a exemplo da mediação interdisciplinar no ambiente escolar.

A relevância do trabalho diz respeito à importância da fomentação da mediação de conflitos para a pacificação social como forma de desconstrução do alto grau de litigiosidade culturalmente presente em nossa sociedade.

\section{AMBIENTE ESCOLAR E SEUS CONFLITOS}

É na educação que se vislumbra as maiores possibilidades de alterações comportamentais e culturais com uma maior esperança de mudança social futura.

Somente a partir do respeito e reconhecimento ao outro, da superação de valores voltados ao individualismo, modificando-os para valores em prol do bem comum é que a crise social e moral poderá iniciar seu processo de superação.

Não foi sem razão que Jacques Maritain (1943), quando apresentou proposta para a 
formação de um humanismo integral no século passado, defendeu que à educação competiria tarefas adicionais no sentido de formar um pensamento humanitário e humanizador, aduzindo que:

\begin{abstract}
Consideremos ahora las tareas especiales que la presente crisis de la civilización y las condiciones de nuestro mundo alocado impondrán sin duda a la educación. Ante la actual desintegración de la vida de família, la crisis de la moralidade y la ruptura entre religion y vida; ante la crisis del Estado y de la consciência cívica y la necesidad de los Estados democráticos de reconstruirse según um ideal renovado, se presenta por doquier la tendência a encargar a la educación que remedie todas esas deficiências.(MARITAIN, 1943, p.3).
\end{abstract}

Ao educador também, complementa o autor, cabe uma tarefa adicional em proveito de uma vida social que envolva o bem estar comum a todos, afimando que "el deber de los educadores es claramente doble: simultaneamente deben cumplir los deberes esenciales de la educación humanista y adaptarlos a las exigências presentes del bien comum”. A importância desse compromisso se revela para todos os seres sociais e que sofrem com a crise moral que se instala com o individualismo e o consumismo amplamente estimulados pelo sistema capitalista.

A violência se apresenta como um fenômeno social envolvido por determinantes da macroestrutura e que se refletem diretamente nas relações sociais microcósmicas, influenciada por contextos culturais e, ainda, históricos.

Um fator preocupante e variável na compreensão do fenômeno tem se caracterizado por não ser apenas a desigualdade social, mas também o fato de estar ocorrendo um esvaziamento dos conteúdos culturais e éticos no processo das relações sociais e que vem sendo continuamente pulverizado para as novas gerações.

Muitas ações, resultado desse esvaziamento, culminam em violências as mais diversas, por intolerâncias e desrespeitos, cujo significado fica melhor explicitado com a afirmação de que “Todo e qualquer ato de agressão - física, moral ou institucional - dirigido contra a integridade de um ou vários indivíduos ou grupos, é considerado ato de violência”. (CHAUÍ, 1999, p. 337).

Evidencia-se, ainda, a violência simbólica, que atinge de forma mais sutil a subjetividade moral sem que seja eliminado o constrangimento provocado pelas agressões físicas, e impostos às classes minoritárias e que se exercem por intermédio da comunicação e do desconhecimento e do sentimento. (BOURDIEU, 2009, p. 10-15). 
Não há comportamento humano determinado geneticamente, e todos os seres humanos são capazes de manifestarem os mais diversos tipos de comportamento a exemplo da bondade, crueldade, nobreza, egoísmo, sensibilidade, alegria, covardia entre tantos outros. O comportamento não é fruto de uma genética, mas sim de experiências acumuladas ao longo da vida em interação com a própria genes. (MONTAGU, 1978, p.11-12).

Hábitos culturais apreendidos em família também se reproduzem no ambiente escolar e se complementam com o aprendizado cultural adquirido e reproduzido nas escolas, como nos ensina Nogueira (2006, p. 23-31), interpretando o sociólogo francês Pierre Bordieu, ao afirmar que são três os modos em que a cultura é absorvida pelo indivíduo. O primeiro é o aprendizado que se efetua desde os primórdios da infância, ainda no seio da família, o segundo é formado pela estrutura social e um terceiro, tardio, realizado pela ação pedagógica, que, nos termos do filósofo francês, seria a interiorização da exterioridade.

A escola vivencia inúmeros conflitos por se calcar em um formato que se distancia das transformações em que a sociedade passa e que exigiria uma escola aberta ao diálogo, aberta às criticas e ao protagonismo da juventude. Os jovens possuem valores diversificados de sua própria vivência e que em contato com ambientes escolares rígidos, reprodutores do sistema, entram invariavelmente em choque. A violência simbólica perpetrada nas instituições, cuja garantia de manutenção se faz representar por meras punições, promove amplos embates. Essa rejeição se apresenta sobre a forma de violências que se propagam pelo patrimônio material e atingem os profissionais da instituição. (CHARLOT, 2002, p. 435).

Os estudiosos de diversas áreas não divergem, e até argumentam, que as condutas agressivas entre alunos podem ser corrigidas por meio de programas individuais ou em grupos. A base de tais posturas deve ser o respeito aos direitos do ser humano, desde a família até aos colegas e profissionais que atuam no ambiente escolar.

A violência realizada na própria família é disseminada e reproduzida dentro da escola demonstrando a forte necessidade de estabelecimento de politicas internas que favoreçam o diálogo e aproximação entre seus atores para promoção de linguagens com discursos destituídos de padrões antigos e com vistas ao esclarecimento da compreensão de que posturas cidadãs implicam direitos e deveres para consigo e para com o outro.

Constatou-se que não existe na escola um trabalho voltado para atrair a família, para discutir as questões que envolvem o grupo etário que ela abriga, seja com relação a assuntos referentes à aprendizagem, seja com relação à disciplina e, especificamente, 
a violência na escola e na sociedade como um todo. Neste sentido, opera-se um distanciamento entre práticas escolares e a família que se veem isoladas, afastadas uma da outra, ao invés de juntarem forças [...] (COUTO, 2013, p. 312).

Ensina Vezzulla, (2013, p.64-65) ao abordar as influências sociais sobre o indivíduo que o "homem como ser situado vê e compreende pelos olhos que lhe são dados pela cultura que vive. A transcendência da comunidade radica no fato de que pertencer a ela significa ser 0 homem pensado por e para a comunidade.”

Pensar em possibilidades de alcance deste processo de diálogo e bem comum é pensar sobre a possibilidade de inserção da mediação nas escolas, sendo a aplicação da mediação interdisciplinar a mais indicada para atendimento e tratamento de questões de grandes destaques como o bullying e outras familiares, em função dos sentimentos envolvidos e da continuidade dos relacionamentos tanto no seio familiar quanto no ambiente escolar.

Pelo Conselho Escolar, a família é chamada para decisões de alta relevância nas escolas de gestão democrática, no entanto, o despreparo para esse processo dificulta ou inviabiliza sua influência em temas decisivos no meio escolar. Isso porque, ante o poder simbólico exercido pelo corpo diretivo, em boa parte das situações, esses membros da comunidade são facilmente manipulados.

Quando isso não ocorre, são destratados, desvalorizados, ignorados ou simplesmente submetidos ao excesso burocrático. Os conflitos estabelecidos nas escolas, marcados por questões que envolvem sentimentos, sofrimentos, questões culturais e habitualidade de condutas necessitam de uma intervenção cuidadosa e multidisciplinar para, adequadamente, serem tratados, permitindo a construção de um enfoque positivo, prospectivo e libertador.

\section{CONSIDERAÇÕES JURÍDICAS}

O conflito faz parte da condição de existência humana, sendo mesmo inerente ao homem, vez que incompatibilidades e desentendimentos são comportamentos que o homem sempre encontrará em sociedade. (MOORE, 1998, p.22).

Os conflitos podem se originar de uma pessoa (inter ou intrapessoais) ou de uma coletividade (Inter coletivos) ou, ainda, podem ocorrer entre duas ou mais nações(internacionais), podendo assumir um enfoque positivo com restabelecimento das relações quando recebem tratamento adequado. (DEUTSCH, 2014, p. 29-33).

No Judiciário, década de 1970, repositório usual de conflitos, instaurou-se uma crise 
de credibilidade vinculada à insatisfação com os trabalhos realizados e a associação a um serviço público ineficiente, lento e insatisfatório o que conduziu as discussões para uma correlação direta entre a insatisfação do público e o Acesso à Justiça. (AZEVEDO, 2013,p.34).

Nesse contexto, Capelletti (1988, p. 31-73) defendeu que o movimento pelo Acesso à Justiça perpassou por três períodos ou ondas: a) a primeira onda se caracterizou pela busca ao mero acesso ao poder judiciário; b) a segunda onda pelo acesso aos interesses coletivos e difusos e; c) a terceira, e última onda, clamou pelo alcance do Justo, de uma forma mais ampla, mediante a utilização de métodos alternativos de disputas para abordagem dos conflitos e alteração em toda estrutura e não somente no Poder Judiciário mas também englobando ações no campo social como um todo.

Assim surge a possibilidade de utilização de métodos autocompositivos dentro e fora do Poder Judiciário, destacando-se a mediação e a conciliação.

No contexto das medidas para promoção da pacificação social, destaca-se a lei da Mediação e o procedimento da mediação inseridos no Código de Processo Civil, ambos publicados no ano de 2015.

O Código de Processo Civil em vigor, lei 13.105/2015, aborda a mediação já no artigo terceiro, parágrafo terceiro, apregoando que a conciliação e a mediação, além de outros métodos, devem ser estimuladas por todos os operadores de Direito, dentro ou fora do Judiciário. Destacam-se os princípios que regem a conciliação e a mediação e a capacitação de mediadores e conciliadores. (BRASIL. Art. 165 a 175, 2015).

A lei da mediação, 13.140/2015, que passou a vigorar 180 dias após sua publicação, trata sobre a autocomposição entre particulares e no âmbito da administração pública e autoriza a qualquer pessoa, em seu nono artigo, que detenha a confiança das partes envolvidas em conflitos, a ser um mediador extrajudicial, desde que devidamente treinada.

Essa lei define a mediação como sendo: “atividade técnica exercida por terceiro imparcial sem poder decisório, que, escolhido ou aceito pelas partes, as auxilia e estimula a identificar ou desenvolver soluções consensuais para a controvérsia.” (BRASIL, art. $1^{\circ}$, parágrafo único). Em seu artigo 42 estende seus benefícios e indica sua atuação em diversos ambientes, a exemplo das mediações comunitárias, escolares e serventias extrajudiciais. 
Denota-se daí que, após o treinamento devido, poderão os próprios componentes das escolas manter atividades contínuas de mediação, o que possibilitaria o diálogo assistido e intermediado para alcance de consensos importantes no ambiente escolar.

Verifica-se, com a publicação da lei do bullying, 13.185/2015, uma preocupação do legislador com as questões de violências nas escolas, instituindo seu combate e o conceituando como sendo:

[...] todo ato de violência física ou psicológica, intencional e repetitivo que ocorre sem motivação evidente, praticado por indivíduo ou grupo, contra uma ou mais pessoas, com o objetivo de intimidá-la ou agredi-la, causando dor e angústia à vítima, em uma relação de desequilíbrio de poder entre as partes envolvidas.(BRASIL, $\S 1^{\circ}$, art. $1^{\circ}$ ).

Dentre o tratamento indicado para este mal presente no ambiente escolar, está a promoção de medidas para uma conscientização, combate e prevenção para práticas que sejam cometidas por alunos ou professores, além de outros profissionais que integram a escola ou a comunidade escolar. A lei, com características sócio-educativas, privilegia o combate terapêutico e preventivo em lugar da criminalização a vítimas e ofensores. (BRASIL, art. $4^{\circ}$, IX, lei 13.185/2015).

Em que pese a publicação dessa lei ter ocorrido meses depois da publicação da lei de mediação de conflitos, verifica-se que, lamentavelmente, não houve a indicação expressa da implementação dessa prática para o combate adequado desse mal social dentro das escolas.

A mediação, em que pese não estar constando na referida lei, é um meio eficiente para o estímulo à discussões e orientações dessas e outras questões escolares, bem como instrumento útil à prevenção e combate a violências institucionalizadas de diversos tipos, promovendo a responsabilização de cada um por seus próprios atos, como recomenda o artigo $4^{\circ}$ da lei em comento.

Indica, a lei de bullying, a institucionalização de ações que promovam a capacidade de desenvolver empatias, o respeito a terceiros e a tolerância, conduzindo ao o alcance de uma cultura de paz (Art. 4 , VII). Tais ações são passíveis de serem alcançadas por meio da mediação de conflitos e por isso essa metodologia de tratamento tem sido aplicada nos ambientes escolares de vários Estados, a exemplo de Brasília, Goiânia e Rio Grande do Sul.

A implementação da Resolução 125/2010 pelo Conselho Nacional de Justiça, cujo objetivo de pacificação social encontra-se listado nos artigos $2^{\circ}$ ao $4^{\circ}$, discrimina a 
necessidade de disseminar a cultura da pacificação social, estimulando a adequada formação e o treinamento de servidores, conciliadores e mediadores, com qualidade (art. $2^{\circ}$ ); há um estimulo a reforçar os agentes apoiadores da implantação de políticas públicas do Conselho Nacional de Justiça junto aos Tribunais do país (art. $3^{\circ}$ ); e, ainda, estimula os tribunais a realizar planejamento de amplos programas de incentivo à autocomposição e à pacificação social. (art. $4^{\circ}$ ).

Essa resolução se apresenta como uma política pública de métodos consensuais a ser aplicada em todo o Judiciário do Brasil e foi o elemento desencadeador de fortes e importantes mudanças nesse campo de atuação.

Dentre as recomendações da Resolução 125 do Conselho Nacional de Justiça estão a conciliação e a mediação como instrumentos de pacificação social para solução e para a prevenção dos mais diversos litígios. E, em que pese ser Política Pública aplicável ao Poder Judiciário, em seu artigo $5^{\circ}$ recomenda a participação de uma rede que deve ser constituída por diversos órgãos, além do Poder Judiciário, incluindo entidades públicas, entidades privadas e instituições de ensino.

A Lei de Diretrizes e Bases, lei de $n^{0}$ 9394/96, instituiu normas de gestão democrática para o sistema de ensino, normas que se traduzem, na prática, na criação de legislação própria das escolas para participação de todos nas decisões, mediante a formação de conselhos, formados pelos que fazem o ambiente escolar, desde professores, alunos, servidores e comunidade, estes últimos representados pelos pais de alunos (art. 14), o que justifica a presença obrigatória da comunidade no ambiente escolar.

É essa a diversidade de compositores da escola que, em seus amplos relacionamentos, se envolvem no mais diversos tipos de conflitos, sendo, a maioria deles de amplo aspecto e de projeção e reprodução na sociedade.

Pela prática da mediação é possível absorver hábitos não adversariais e autocompositivos onde fica evidenciada a ligação entre o individuo e a família e o indivíduo e a coletividade. (VEZZULA, 2013. p. 72).

A mediação promove, dessa forma, o encontro dos diálogos, possibilitando exposição de razões e interesses e auxilia na mudança da visão de conflito de um enfoque negativo, permeado de discussões e desavenças, para um enfoque positivo, de compreensão, entendimento e soluções construídas. Procedimentos esses que cabem em todos os campos de 
atividade humana.

\section{MEDIAÇÃO INTERDISCIPLINAR}

Ao abordar o tema mediação, falando-se especificamente sobre seu significado, Barbosa (2015, p. 20) remete sua análise à construção de um princípio jurídico e de moral universal.

Nesse contexto, apresenta, antes mesmo de sua definição, tudo aquilo que não pode ser associado à mediação de conflitos. Destacando, inicialmente, que a mediação não pode ser um tratamento jurídico menor ou subqualificado que visa tão somente encerrar o processo ou o conflito e desafogar o Poder Judiciário.

Também não deve ser vinculada à ideia de ser mera assistência psicológica, que em muito se difere dessa atividade, posto que deve ser realizada por profissionais próprios da área e não pode, de nenhuma maneira, ser imposta, já que participar de processos psicoterapêuticos é ato voluntário do indivíduo. (BARBOSA, 2015. p. 36).

A mediação de conflitos, na ótica de Fernanda Tartuce, é assim é definida:

\footnotetext{
A mediação de conflitos é o meio consensual de abordagem de controvérsias em que uma pessoa isenta e devidamente capacitada tecnicamente para facilitar a comunicação entre as pessoas para propiciar que elas possam, a partir da restauração do diálogo, encontrar formas proveitosas de lidar com as disputas. (TARTUCE, 2016, p. 52).
}

A mediação possui natureza disciplinar quando tem por escopo único a solução dos conflitos, enquanto que esta natureza passa a ser de caráter interdisciplinar quando seu objetivo maior é o de transformar o conflito. (TARTUCE, 2016, p. 52).

O Código de Processo Civil, lei 13.105/2015 aponta que o mediador deverá atuar “preferencialmente” onde haja vínculos anteriores entre as pessoas e que deve auxiliá-las a compreender questões e interesses envolvidos no conflito e possa então construir, em conjunto com os envolvidos, soluções consensualizadas e com mútuos benefícios. (BRASIL, 2015, art. 165, § $\left.3^{\circ}\right)$.

Relações continuadas são certamente as relações familiares, embora não sejam as únicas. As relações entre vizinhos são também exemplos de relações continuadas e as relações 
escolares, onde por longos anos os componentes desse ambiente mantém contatos contínuos e diários, também estão inseridas nessa recomendação.

Destaca-se a definição de mediação apresentada por Goldberg que afirma “mediation is negotiation carried out with the assistance of a third party”.(GOLDBERG, 2003, p. 111). Para Helena Soleto Munoz (2009), a mediação “[...] es un procedimiento através del cual um tercero imparcial ayuda a las partes en conflicto a llegar a un acuerdo. La esencia de la mediación que refleja esta definición es la autonomia de la voluntad de las partes”.

A aplicação da mediação, a depender das situações e características dos conflitos a serem conduzidos, pode assumir diversos tipos e diferentes atuações, a exemplo da mediação tradicional disciplinar, da mediação comunitária, mediação vítima-ofensor, mediação de pares, da mediação interdisciplinar e até mesmo dos círculos restaurativos.

A mediação interdisciplinar se caracteriza por ser realizada com o aporte de outras disciplinas a exemplo da psicologia, psicanálise, assistência social e sociologia, mostra-se muito adequada para o tratamento de questões voltadas a perdas e frustrações das pessoas em situação de fracasso de seus projetos pessoais. (TARTUCE, 2016, p. 331).

Ante a perenidade presente nas relações escolares e familiares, a mediação de conflitos com a especialidade multidisciplinar tem sido indicada na literatura para lidar com continuidade de relacionamentos e necessidade da transformação do conflito para um enfoque positivo.

A família é núcleo de socialização de indivíduos e seu funcionamento se baseia em dinâmicas de poder e afeto, numa interação entre cooperação e disputas. Assim, o caminho mais adequado para solução dos conflitos que nela surge é o da mediação interdisciplinar, vez que a investigação dos interesses alcança aspectos subjetivos do conflito.

Essa metodologia permite a reconstrução dos conflitos familiares posto que envolvem relações interpessoais de continuidade, e ante a possibilidade de transformação do conflito de forma a fortalecer tais relações, já que inexistem ganhadores e perdedores em seu resultado. "Daí se adotar, com este método, o caminho dialético, possibilitando a comunicação entre os dissidentes, a transformação da relação conflituosa e a construção de um acordo satisfatório e eficaz.” (SILVA, 2013, p. 170).

Tal assertiva é reforçada por Aguida Arruda Barbosa ao concluir que: 
Ressalte-se que a mediação interdisciplinar é capaz de proteger os filhos do divórcio, reduzindo o comprometimento psicológico e psicossomático, presentes nas crianças que vivem a ruptura do casal conjugal de seus pais, que, na grande maioria, não conseguem deixar de contaminar as funções materno-paterno-filiais.” (BARBOSA, 2015.p.40).

Observa-se, contudo, que no ambiente escolar, tais premissas de continuidade de relacionamentos e sentimentos envolvidos nos conflitos também estão presentes, o que nos faz perceber a possibilidade de aplicação da mediação em seu caráter e conteúdo interdisciplinar.

A natureza interdisciplinar da mediação significa que o mediador, nessa atividade, deve se desvincular da sua profissão de origem e buscar conhecer outras matérias que complementarão e darão o suporte necessário para o sucesso desse trabalho. Assim, ao mediador, independente de sua formação, cumpre buscar conhecimentos nas áreas de negociações, áreas de esquemas financeiros, assuntos de relacionamentos humanos, aspectos legais e aplicação do Direito.

Desnecessária a formação profissional em todas essas disciplinas, posto não ser o mediador especialista nessas áreas, contudo, os conhecimentos diversificados serão de muita utilidade para a condução dos diálogos, e, ao perceber, necessidade de intervenção desses profissionais deverá recomendar aos envolvidos que o profissional deva ser consultado para esclarecimentos mais amplos e formação de melhor compreensão antes de se tomar qualquer decisão. (GRUSPUN, 2000, p. 87).

É assim que a interdisciplinaridade se traduz na busca incessante do indivíduo por uma ampliação do conhecimento, significando "um saber que toma por empréstimo os saberes de outras disciplinas, integrando-se num conhecimento de um nível hierarquicamente superior”. (BARBOSA, 2015, p. 74).

É esse o aspecto positivo da linguagem da interdisciplinaridade na mediação, traduzida na atividade e capacidade de ampliar a visão para enxergar além da divergência trazida pelos envolvidos, com apoio nos conhecimentos adquiridos de outras ciências e percebendo a pluralidade de motivações que deram ensejo ao conflito, podendo, assim, auxiliar nas soluções para as demandas da escola.

Para muitos juristas e operadores do Direito a prática da mediação se presta para desafogar o Poder Judiciário e é certo que as alternativas consensuais surgem a partir do 
contexto da crise da Justiça. (PELEGRINI, 2008, p. 2). Esse entendimento, contudo, merece ponderações vez que a mediação isoladamente não possui o condão de desafogar o judiciário.

No entanto, uma vez apreendido o comportamento de superação de barreiras em ambientes educativos, tal aprendizado poderá colaborar para, no futuro, não surgirem novas demandas já que solucionadas pacificamente pela autocomposição, sendo, assim, “o desafogamento” do Judiciário uma consequência futura.

Em relação ao efeito, assegura a literatura, tratar-se de um inegável processo de auto cura, pois reestabelece o envolvido no conflito ao seu sistema familiar, capacitando-o para as decisões e escolhas adequadas e possíveis em todo o processo de discordância e litigio com o outro. Observa-se, assim, que o efeito da mediação passa a se constituir em uma terapia guiada pela ética do zelo e multiplicada com os efeitos pedagógicos da aprendizagem, inseridos no processo. (BARBOSA, 2015, p. 123).

Como forma de ampliação da política pública já instituída no Judiciário, surge a necessidade de outras políticas públicas a serem aplicadas no ambiente escolar por meio de projetos pilotos, mediante análise da situação local e de seus resultados e benefícios, para promoção da ampliação para outros campos de atividades.

Nesse contexto, estando a instituição preparada com seu corpo profissional treinado para atuar com a mediação de conflitos, os jovens, profissionais e familiares dos alunos em dificuldades detectadas pela coordenação, poderão passar, desde que voluntariamente, por esse processo para superação dos mais diversos conflitos que interferem na vida familiar e no ambiente escolar.

Esse procedimento multidisciplinar se aplica muito bem para a prevenção e trato de ações voltadas para o tratamento do bullying nas escolas e para as questões familiares, vez que capacita os indivíduos para resolver os seus problemas com enfoque positivo de resgate e fortalecimento das relações e, ainda, promove a educação para incorporação dessas posturas diante de novos conflitos, auxiliando na reorganização da vida escolar e do grupo familiar.

\section{DIGNIDADE HUMANA E CULTURA DA PAZ}

No Brasil, a violência decorre, dentre outros fatores, da insuficiência de acesso aos bens e aos serviços que garantiriam a dignidade humana aos indivíduos de baixa classe social 
e a incapacidade de ingerência dos poderes públicos para um atendimento, de forma adequada, a esse grupo social, sempre marcado pela impunidade promovida, em muitas situações, pelos próprios agentes públicos eleitos ou nomeados com o escopo divulgado, para sua eleição, de defender os interesses da comunidade.

Verifica-se que o conflito desencadeia a violência em função da negação da palavra e de um espaço definido nos ambientes de decisões acerca do convívio humano. Isso ocorre nas escolas e se multiplica em diversos ambientes.

A Dignidade Humana é qualidade própria, intrínseca, interna de cada ser e que o faz ser merecedor de respeito e de reconhecimento pelos demais indivíduos, pelo Estado e pela comunidade. (SARLET, 2012, p. 73).

Após o período da segunda guerra mundial, a alegação dos nazistas de estar cumprindo um dever legal para a dizimação de povos judeus suscitou inúmeras críticas a uma concepção de ordenamento que se mostrou indiferente aos valores éticos e presos a uma forma de visão meramente formal. (PIOVESAN, 2012, p. 183-191). Historicamente, o tema se apresenta como uma crítica ao positivismo jurídico que defendia a aplicação da lei, por seus próprios fundamentos.

Soma-se a isso a ideia de liberdade e de autonomia, e, a partir daí, busca-se uma vinculação a um principio universal impregnado de moralidade e que deve servir de fundamento a toda ação humana. O estabelecimento e o reconhecimento de condições imprescindíveis para uma vida digna passam a fundamentar a ética dos direitos humanos. (RAMOS, 2015).

O princípio da dignidade da pessoa humana passa a impor limites à atuação do Estado, com vistas a impedir que este viole a dignidade pessoal de cada ser. O que implica uma construção de um dever de constituição de uma meta permanente a proteger, realizar e promover ações concretas para uma vida digna a todos os seus cidadãos. A remoção dos obstáculos a esses propósitos, de vida digna para todos, também faz parte dos objetivos a serem alcançados pelo Estado, devendo especialmente se criar "condições que possibilitem o pleno exercício e fruição da dignidade [...]”. (SARLET, 2012, p. 58).

Não pode ser outra a tradução dos diversos documentos normativos internacionais da Organização das Nações Unidas e Unesco que versam sobre a Educação, a ciência e a cultura.

Exemplos de tais documentos são: a Declaração Universal dos Direitos da Criança, a 
Declaração sobre o Direito dos Povos à Paz, a Declaração sobre a Preparação das Sociedades para Viver em Paz e a Declaração sobre uma Cultura de Paz, todas fundamentadas pelo princípio da dignidade e construção da paz.

Daí se aduz a possibilidade de implantação de uma politica que envolva a prática da mediação de conflitos no ambiente escolar, fomentando-se o desenvolvimento de habilidades comunicativas para o pleno desenvolvimento do ser, em ambiente de farta reprodução comportamental, e já tratando os conflitos existentes com o processo educativo do diálogo, da compreensão e das responsabilidades de cada um a nortear os comportamentos e ações.

Olhar o outro de forma a respeitar as diferenças e construir soluções adequadas, personalizadas e justas é conferir tratamento digno aos integrantes do ambiente escolar.

A comunicação não violenta, no dizer de Rosemberg (2006, p. 21) "se baseia em habilidades de linguagem e comunicação que fortalecem a capacidade de continuarmos humanos, mesmo em condições adversas”. É exatamente este o espírito da mediação de conflitos, garantir o direito de fala e de construção de soluções alternativas que visem a melhoria na qualidade dos relacionamentos.

Um olhar ao nosso redor é suficiente para percebermos que nossa sociedade, de característica tecnocrática, apresenta, ao longo de sua história, profundos problemas sociais, ecológicos e políticos que são reproduzidos pela educação e pela mídia, cultivando, quase sempre, valores como a competitividade, o sucesso a qualquer título, a lógica fria, bem como o consumo muitas vezes de forma excessiva.

Vivemos uma realidade impregnada de uma cultura demandista acostumada a tudo confiar a um juiz, acreditando ser este mais capaz de solucionar os conflitos.

A construção de uma cultura de paz requererá uma mudança nos padrões mentais e nas nossas ações diárias. Na escola atual, reprodutora da cultura formada, tal desiderato não ocorrerá sem que ações efetivas e impulsionadoras de mudanças se insiram no contexto. "Relevante se faz, assim, mudar o paradigma, recodificando valores e hábitos, de cultura da conflituosidade (antagonista) rumo à cultura da pacificação (convivencial).” (SILVA, 2013, p. 161).

O ensino de um ofício, na ótica de Bordieu (2009, p. 22), deve ser transmitido por meio de um modo prático "firmado no contacto directo e duradouro entre aquele que ensina e aquele que aprende $[. .$.$] ”.$ 
Demonstra-se, assim, a importância que deve ser dada ao conhecimento prático, que, em na análise do filosofo, silenciosamente se firma e se apreende. Senão vejamos o que nos diz:

\begin{abstract}
Os historiadores e os filósofos das ciências - e os próprios cientistas, sobretudo têm frequentemente observado que uma parte importante da profissão de cientista se obtém por modos de aquisição inteiramente práticos - a parte pedagógica do silêncio, dando lugar a explicitação não só dos esquemas transmitidos como também dos esquemas empregados na transmissão, é sem dúvida tanto maior numa ciência quanto nela são menos explícitos e menos codificados os próprios conteúdos, saberes, modos de pensamento e de ação.”(BORDIEU, 2009, p. 22).
\end{abstract}

Ora, denota-se que o conhecimento advém não só do que se transmite de forma verbal ou escrita, como também do comportamento e forma como estes são também transmitidos.

Uma forma de superação de barreiras é desenvolver um vocábulo que expresse os sentimentos, permitindo a demonstração das vulnerabilidades, isso conecta melhor as pessoas envolvidas no conflito. (ROSEMBERG, 2006. p. 76)

A prática da mediação, nesse contexto, evidencia-se como hábito positivo a influenciar ações e práticas de todos os envolvidos no processo. Nesse aspecto, a construção da cultura da paz requer ações, conhecimentos, habilidades, atitudes e valores que possam conduzir a novas reflexões, prevenindo novos conflitos e violências habituais.

Educar para a paz representa um envolvimento capaz de gerar oportunidades para encontro de diversidades, significados e afetos, transformando a escola em espaços de ensino/aprendizagem práticos reais, em ambientes humanizados e de ampla sensibilidade.

A prática da mediação tem por princípio o exercício pleno da cidadania com a construção das responsabilidades individuais de cada ser, por meio do poder de decisão, relativos a si próprios e a seu semelhante.

A nova perspectiva metodológica para a Administração da Justiça reflete uma tendência cada dia mais frequente em observar o operador do Direito como um pacificador.

A mediação praticada fora do judiciário representa um moderno modelo de acesso à justiça, pois, permite que as pessoas possam, de forma construtiva e por si sós, resolverem seus conflitos, promovendo relacionamentos mais participativos, reduzindo a competitividade e contribuindo com a manutenção e fortalecimento dos relacionamentos, implementando-se, 
assim, estratégias educativas para soluções conjuntas de futuros conflitos por meio de uma educação de compreensão mútua.(AZEVEDO, 2013, p. 9-14).

Percebe-se que implementar uma cultura da pacificação requer a implantação de práticas efetivas no processo educativo, sendo essa a contribuição a que se propõem as linhas reflexivas aqui traçadas.

\section{CONCLUSÃO}

Notícias da atualidade, que apresentam cenas preocupantes acerca da violência em todos os campos sociais, a exemplo das crianças vítimas da guerra na Síria, da violência contra a mulher, abandono de sociedades indígenas, preconceitos raciais, abandono de idosos e pessoas vítimas da fome e da seca no interior do nordeste, representam exemplos de tratamentos desumanos amplamente praticados que nos fazem refletir sobre o destino do homem e sua caminhada para o futuro.

O compromisso social é compromisso de todos e não pode e nem deve se resumir a uma responsabilização pura e única a ser atribuída ao Estado, sem que nada possa ser modificado ou empreendido de forma individualizada.

Normas ou regras não modificam uma cultura, por si só. Mudança cultural não ocorre em um tempo determinado e de uma única vez. Pensar em alternativas para a mudança comportamental é tarefa de todos.

A mediação de conflitos proporciona inúmeras vantagens para o restabelecimento do bem estar e da convivência harmoniosa entre os indivíduos.

As soluções criativas adaptadas ao contexto, algumas jamais pensadas pelo próprio legislador ou aplicador do Direito, são capazes de suprir a deficiência e até mesmo a inexistência de serviços públicos. Nesse processo se estabelece uma ponte entre o possível e o ideal de forma a atingir interesses mútuos e a medida de justiça presente em cada um dos integrantes do processo.

Essa prática se mostra um procedimento possível de se realizar com todas as pessoas, o que preconiza o caráter democrático e de participação múltipla. Conduz, ainda, ao senso de responsabilidade e iniciativas do indivíduo na construção de uma solução de paz, colaborando diretamente com a pacificação social. Sua informalidade denota uma melhor aceitação o que 
gera amplas possibilidades de bons resultados.

O ambiente escolar necessita de ações práticas que proporcionem o diálogo e o crescimento da noção de responsabilidade, respeito e resgate de valores e que demonstrem a importância dos relacionamentos sociais.

A inserção de práticas de mediação nesse processo educacional, promovendo os diálogos e estabelecendo regras de convivência, com soluções que exsurgem dos próprios integrantes do ambiente, refletirá pedagogicamente como excelente prática de complementação educacional a ampliar a comunicação e apontar possibilidade para a redução de recursos torpes ou violentos na solução de desavenças e desentendimentos gerados nos conflitos em geral.

A mediação interdisciplinar, por sua característica mais voltada à transformação das controvérsias em oportunidade de melhoria nos relacionamentos e aprendizado, para superação positiva dos conflitos, se apresenta muito mais adequada para sua aplicação nas escolas, mais precisamente para os problemas enfrentados com o bullying e também o atendimento das famílias ou questões a ela relacionadas e pelos profissionais e comunidade inseridos nesse contexto.

Preparar o indivíduo para a superação dos conflitos, permeada de cuidados, e voltada para o restabelecimento positivo dos relacionamentos, dentro do ambiente escolar, é preparar para a vida em sociedade, sobretudo voltada para o crescimento da responsabilidade de um com o outro. Isso representa o tratamento social de dignidade e respeito e o caminho para uma real pacificação social.

A família inserida no ambiente escolar, seja nos conselhos, seja no manejo com mestres e coordenadores, merece tratamento digno, voz e vez dentro das escolas. Para que isto possa ocorrer a escola precisa se organizar democraticamente, transformando familiares e comunidades ao redor em colaboradores do processo educativo.

A cultura da paz, em uma de suas dimensões, se relaciona com o humano que existe em cada um de nós, que aprende tanto a fazer a guerra como a edificar a paz. Ela está presente em todos os cantos e recantos da sociedade, estando o ambiente ensino aprendizagem e a educação que nele se pratica inseridos nesse contexto. Resta agora a concretização de projetos que alcancem as pessoas através de ações práticas que atendam a dignidade inerente a todos nós. 


\section{REFERÊNCIAS}

AZEVEDO, André Gomma. Novos desafios de acesso à justiça. In: SILVA, Luciana Aboim Machado Gonçalves da (Org). Mediação de conflitos. São Paulo: Ed. Atlas, 2013. p. 3-22.

BARBOSA, Águida Arruda. Mediação familiar interdisciplinar. São Paulo: Atlas, 2015.

BRASIL. Lei 13.105/2015, de 16 de março de 2015. Código de processo vivil. Diário Oficial [da] República Federativa do Brasil. Brasília, DF, 16 mar. 2015. Disponível em <http:/www. planalto.gov.br/ccivil_03/_ato2015.2018/2015/lei/13105.htm>.acesso em 10 maio 2017.

BRASIL. Lei n. ${ }^{\circ}$ 13.140, de 26 de junho de 2015. Dispõe sobre a mediação entre particulares como meio de solução de controvérsias e sobre a autocomposição de conflitos no âmbito da administração pública. Diário Oficial [da] República Federativa do Brasil. Brasília, DF, 26 jun. 2015. Disponível em <http://www.planalto.gov.br/ccivil_03/_ato2015-2018/2015/Lei/ L13140. htm >. Acesso em: 08 maio 2017.

BORDIEU, Pierre. O poder simbólico .Tradução de Le Pouvoir symbolique. 12 ed. Rio de Janeiro: Bertrand Brasil, 2009.

CAPELLETTI, Mauro. Acesso à justiça. Trad. Ellen Gracie Northfleet. Porto Alegre: Fabris, 1988.

CHARLOT, Bernard. A violência na escola: como os sociólogos franceses abordam essa questão. In: Sociologias. Porto Alegre, ano 4, nº 8, jul/dez, 2002, p. 432-443.

CHAUÍ, Marilena. Convite à filosofia. São Paulo, Ática, 1999.

COUTO, Maria Aparecida Souza. Representações de masculinidades e identidade de gênero de estudantes do ensino médio e a relação com as violências na escola pública. 2013. Tese. (Doutorado em educação), da Universidade Federal de Sergipe, São Cristóvão, 2013. Disponível em <http://bdtd.ufs.br/handle/TEDE/1558>.Acesso em: 10/05/2017.

DISKIN, Lia. ROIZMAN, Laura Gorresio. Paz, como se faz? Semeando cultura de paz nas escolas. 4. ed. Brasília: UNESCO, Associação Palas Athena, Fundação Vale, 2008. Disponível em < http://unesdoc.unesco.org/images/0017/001785/178538por.pdf>. Acesso em 11/05/2017.

DEUSTSCH. Morton. A resolução do conflito. In: AZEVEDO, André Gomma de. (org.). Estudos em arbitragem, mediação e negociação. Vol 3. Brasília: Grupos de Pesquisa, 2004.

GOLDBERG, Stephen B., SANDER, Frank E.A ., ROGERS, Nancy H., COLE, Sarah R. Dispute Resolution - negociation, mediation, and other processes, $4^{\mathrm{a}}$ edition, New York:Aspen Publishers, Inc, 2003, p.111. 
GUIMARÃES, Marcelo Rezende. Desafios para a construção de uma cultura de paz. In: Seminário Direitos e Educação para a paz. 1. Brasilia: 8 e 9 de dezembro, 2005.

GRUSPUN, Haim. Mediação familiar: o mediador e a separação de casais com filhos. São Paulo: Ltr, 2000.

JACQUES Maritain. Una educacion integral para um humanismo integral. Disponível em <http://www.jacquesmaritain.com/pdf/10_EDU/04_ED EduHI.pdf>. Acesso em: 11 maio 2017.

MOORE, Christopher W. O processo de mediação: estratégias práticas para a resolução de conflitos. Tradução Magda França Lopes. 2. ed. Porto Alegre: Artmed, 1998.

MONTAGU, Ashley. A natureza da agressividade humana. Rio de Janeiro: Zahar, 1978.

MUNOZ, Helena Soleto. La Mediación: método de resolución alternativa de conflitos em el proceso civil español, in: Revista Eletrônica de Direito Processual, ano 3, vol. 3, janeiro a junho de 2009. Disponível em http://www.arcos.org.br/periodicos/revista-eletronica-dedireito-processual/volume-iii/la-mediacion-metodo-de-resolucion-alternativa-de-conflictosen-el-proceso-civil-espanol>. Acesso em: 17 maio 2017.

NOGUEIRA, Maria Alice; NOGUEIRA, Cláudio M. Martins. Bordieu \& a educação. 2. ed. Belo Horizonte: Autêntica, 2006.

PELEGRINI, ada; WATANABE, Kazuo; LAGRASTA NETO, Caetano(org). Mediação e Gerenciamento do processo: revolução na prestação jurisdicional: guia prático para a instalação do setor de conciliação e mediação, 2. reimp. São Paulo: Atlas, 2008.

PIOVESAN, Flávia. Direitos humanos e o direito constitucional internacional. São Paulo: Saraiva, 2012.

RAMOS, André de Carvalho. Teoria geral dos direitos humanos na ordem internacional. 5. ed. São Paulo: Saraiva, 2015.

ROSEMBERG, Marshall B. Comunicação não violenta: técnicas para aprimorar relacionamentos pessoais e profissionais. Tradução Mário Vilela. São Paulo: Ágora, 2006.

SARLET, Ingo Wolfgang. Dignidade da pessoa humana e direitos fundamentais na constituição federal de 1988. Editora livraria do advogado. Porto alegre, 2012.

SILVA, Luciana Aboim Machado Gonçalves da. Mediação interdisciplinar de conflitos: mecanismos apropriado para resolução de conflitos familiares. In (Org). Mediação de conflitos. São Paulo: Ed. Atlas, 2013. p. 160-180.

VEZULLA, Juan Carlos. A mediação para uma análise da abordagem dos conflitos à luz dos

Revista Cidadania e Acesso à Justiça | e-ISSN: 2526-026X | Maranhão | v. 3 | n. 2 | p. 96 - 116 | Jul/Dez. 2017. 
direitos humanos, o acesso à justiça e o respeito à dignidade humana. In: SILVA, Luciana Aboim Machado Gonçalves da (Org). Mediação de conflitos. São Paulo: Ed. Atlas, 2013. p. 63-93.

TARTUCE, Fernanda. Mediação nos conflitos civis. 3.ed. Rev., Atual., Ampl. Rio de Janeiro: Forense; São Paulo: Método, 2016. 